\title{
A Natural Wonder Drug Helps to Prevent Cancer: Garlic Oil
}

\author{
Sankaran MIRUNALINI, Ganesan DHAMODHARAN, Kandhan KARTHISHWARAN \\ Annamalai University, Faculty of Science, Department of Biochemistry and Biotechnology, \\ Tamil Nadu, India; mirunasankar@gmail.com
}

\begin{abstract}
Garlic is one of the oldest and popular spices in the world that also contain very good nutritional value. Garlic has a wide spectrum of actions not only is it antibacterial, antiviral, antifungal and antiprotozoan but it also has beneficial effects on the cardiovascular and immune systems. They contain unique oil which is very easily digested and is stable to oxidative stress and for this reasons they are useful and healthy for consumption. Several epidemiological and experimental studies suggest that garlic oil has been thought to bring about its anticarcinogenic effect and other pharmacological properties through a number of mechanisms, such as the scavenging of radicals, increasing glutathione levels, increasing the activities of enzymes such as glutathione $S$ transferase, catalase, incubation of cytochrome p450 2E1, DNA repair mechanisms, prevention of chromosomal damage etc. Future research should standardize the dosage of garlic and type. Several hypotheses suggest that the anticancer mechanism may be due to DNA repair mechanism, prevention of chromosomal damage, antiproliferative effect and alteration of the cell cycle. Garlic and garlic oil should be considered as one of the most valuable food for good quality of life in general.
\end{abstract}

Keywords: garlic oil, oxidative stress, antioxidants, anticancer mechanism, free radicals

\section{Introduction}

Cancer is one of the most common and severe cause of death in major parts of the world. Despite advances in early detection and treatment, over all death rates from cancer have remained largely unchanged since the early 1970s, suggesting the need for stronger focus research prevention. Approaches to prevention necessarily include cessation of smoking and alcoholic intake and dietary changes, since each is believed to contribute to about one-third of annual cancer deaths. For two decades, dietary advice to prevent cancer has emphasized fruit and vegetable consumption. Recent recommendation listed in Tab. 1 give highest priority consuming plant based diets. Herbal drugs are being investigated for their anticancer effect. Chemoprevention offers an effective means of controlling the incidence of cancer. Dietary habits have been reported to significantly modify the initiation, promotion and progression stages in carcinogenesis (Schorah, 1999). Garlic (Allium sativum), is used extensively as a spice in foods, exhibits medicinal properties including immunomodulation, hepatoprotection, antioxidant, antimutagenic, antibacterial and anticarcinogenic effects (Agarwal, 1996).

Garlic is a member of the family Liliaceae and has botanical name Allium sativum. Garlic is the oldest cultivated plant and has been used as a spice, food and folklore medicine for over 4000 years and is the most widely researched plant. The word garlic was originated from the Anglo-saxon 'gar-leac' or spear plant. The word Allium is derived from the cetic word meaning pungent or burn- ing. The species name sativum means planted, cultivated or sown. Well over thousand papers have been published in the past 20 years on garlic and related alliums (Heber, 1997).

Codex Ebers, an Egyptician medical papyres dating of about 1550 BC, gives more than 800 therapeutic formulas 22 of which contains garlic as an effective remedy for a variety of ailments. Throughout written history, garlic has been in use and was part of the staple diet of the Egyptician pyramid builders. Several cloves of garlic were also found in the tomb of Tutankamon. It has been mentioned in the bible during the time of exodus that garlic was also associated with the Israelites. Pliny, a roman naturalist, has described in his Historia Naturalis how garlic has been used for gastrointestinal disorders, dog and snake bites, scorpion stings, asthma, madness, convulsions, tumors and consumption. Use of garlic has been recorded by Hippocrates 'the father of modern medicine' as a laxative and diuretic. It is used for the treatment of uterine tumors, by Aristophanes and Galen. During the first Olympic Games in Greece, athletes ingested garlic as a stimulant. Garlic is an indelible component in traditional Chinese medicine, Islamic medicine, folklore medicine, ayurveda and homeopathy. In India, garlic has been used for centuries as an antiseptic lotion for washing wounds and ulcers (Agarwal, 1996).

\section{Chemical composition}

The main components of fresh garlic are water, carbohydrates, proteins, fibres, fat, essential aminoacids, vita- 
Tab. 1. Chemical composition of garlic

\begin{tabular}{|c|c|}
\hline Chemical contents & $\mathrm{g} / 100 \mathrm{~g}$, net weight \\
\hline Moisture(\%) & $61.3-86.3$ \\
\hline Proteins & $2.2-6.2$ \\
\hline Fat & $0.2-0.3$ \\
\hline Carbohydrate & $9.5-27.4$ \\
\hline Ash & $0.6-1.5$ \\
\hline Energy & $39-140$ \\
\hline Bulk elements & $\mathrm{Mg} / 100 \mathrm{~g}$, net weight \\
\hline $\mathrm{Ca}$ & $50-90$ \\
\hline $\mathrm{P}$ & $390-460$ \\
\hline $\mathrm{K}$ & $100-120$ \\
\hline $\mathrm{Na}$ & $10-22$ \\
\hline $\mathrm{Al}$ & $43-77$ \\
\hline $\mathrm{Mg}$ & $0.5-1$ \\
\hline $\mathrm{Ba}$ & $0.2-1$ \\
\hline $\mathrm{Fe}$ & $2.8-3.9$ \\
\hline Trace elements & $\mathrm{Mg} / 100 \mathrm{mg}$, net weight \\
\hline $\mathrm{Sr}$ & $0.1-0.7$ \\
\hline $\mathrm{B}$ & $0.3-0.6$ \\
\hline $\mathrm{Cu}$ & $0.02-0.03$ \\
\hline $\mathrm{Zn}$ & $1.8-3.1$ \\
\hline $\mathrm{Mn}$ & $0.2-0.6$ \\
\hline $\mathrm{Cr}$ & $0.3-0.5$ \\
\hline $\mathrm{Ge}$ & 0.014 \\
\hline $\mathrm{Se}$ & $0.015-0.035$ \\
\hline$S$ & 65 \\
\hline $\mathrm{Cl}$ & 43 \\
\hline Vitamins & $\mathrm{Mg} / 100 \mathrm{mg}$, net weight \\
\hline Thiamine & 0.25 \\
\hline Riboflavin & 0.08 \\
\hline Nicotinic acid & 0.5 \\
\hline Vitamin C & 5 \\
\hline Retinol & 0.015 \\
\hline
\end{tabular}

mins, minerals and volatile sulfur compounds (Tab. 1). In addition garlic oil may be obtained by distillation process in water and alcohol to extract their active ingredients (Fig. 1). Garlic oil is a colour less to pale yellow liquid with a characteristic gastric odor. It contains diallyl disulphide, allylpropyl disulphide and various polysulphides and monosulphides (Fig. 2) (Augusti, 1996). In addition to

Tab. 2. Composition of garlic oil

\begin{tabular}{cc}
\hline Specific gravity $\left(15^{\circ} \mathrm{C}\right)$ & $1.046-1.057$ \\
\hline Refractive index & $1.5578-1.5748$ \\
\hline Diallyl disulbhide & $60 \%$ \\
Allyl propyl disulbhide & $6 \%$ \\
Allicin & $0.3 \%-0.5 \%$ \\
Diallyl sulphide & $30-100$ \\
\hline Diallyl trisulphide & $900-1,100$ \\
Allyl menthyl disulphide & 100 \\
\hline Allyl methyl trisulphide & $250-270$ \\
\hline
\end{tabular}<smiles>C=CCS[GeH3]</smiles><smiles>C=CCSSCC=C</smiles><smiles>C=CCSCC=[AsH]SSCC=C</smiles>

\section{S - Allylmercaptocystin}

Fig. 1. Components of Garlic

that, garlic oil also contains many involatile sulphur compounds also (Tab. 2).

Essential oil has been demonstrated to possess expectorant, diaphoretic, disinfectant and diuretic properties. Steam distilled garlic oil contains fair amounts of DADS and DATS. Garlic macerated oil contains ajoene, highly antibiotic and especially good at inhibiting platelet aggregation and vinyldithiins, which are water-soluble and circulate through the blood system and likely are more

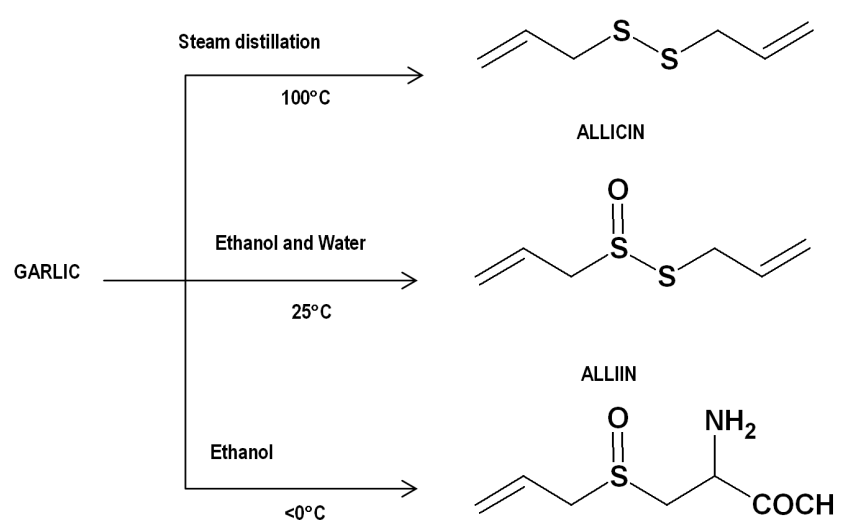

Fig. 2. Sulfur compounds extracted from Garlic under various conditions

Tab. 3. Analyses of undiluted GO

\begin{tabular}{cc}
\hline GO component & Conc.(mg/g)" \\
\hline Diallyl monosulfide & $106 \pm 7(10.6)$ \\
\hline Diallyl disukfide & $530 \pm 7(53.0)$ \\
\hline Diallyl trisulfide & $115 \pm 4(11.5)$ \\
\hline Diallyl tetrasulfide & $43 \pm 2(4.3)$ \\
\hline Diallyl pentasulfide & $10.5 \pm 0.4(1.1)$ \\
\hline Diallyl hexasulfide & $0.14 \pm 0.01(0.01)$ \\
\hline Methyl allyl disulfide & $44.1 \pm 2(4.4)$ \\
\hline Methyl allyl trisulfide & $69.9 \pm 2.2(7)$ \\
\hline Methyl allyl tetrasulfide & $24.6 \pm 2.0(2.5)$ \\
\hline Methyl allyl pentasulfide & $6.3 \pm 0.6(0.6)$ \\
\hline Methyl allyl hexasulfide & $1.5 \pm 0.1(0.2)$ \\
\hline Dimethyl trisulfide & $12.0 \pm 1.3(1.2)$ \\
\hline Dimethyl tetrasulfide & $4.3 \pm 0.6(0.2)$ \\
\hline Dimethyl pentasulfide & $2.0 \pm 0.4(0.2)$ \\
\hline
\end{tabular}


Tab. 4. Epidemiologic studies of consumption of garlic and risk for cancers

\begin{tabular}{ccccc}
\hline Cancers & Country & Cases/controls & Time of reference & OR $^{\text {a }}\left(\mathrm{P}_{\text {-value for trend })}\right.$ \\
\hline Stomach & China & $241 / 241$ (hospital) & Before onset & No significant effect \\
Esophageal & China & $153 / 234$ (Population) & Not specified & 0.30 \\
Colorectal & Switzerland & $223 / 491$ (hospital) & 2 years before diagnosis & Colorectum $0.39(<0.01)$ \\
Breast & France & $345 / 345($ Selected Population) & Before interview & $0.3(0.00001)$ \\
Prostate & England & $328 / 328$ (Population) & 5 year before interview & $0.64(0.13)$ \\
\hline
\end{tabular}

beneficial to the heart and circulatory system. Moreover, garlic oil is also mixed with vegetable oil and made into capsules (Agarwal, 1996).

\section{Active constituents}

The principle active ingredient in garlic oil is allicin, which is present in the form of a thermostable precursor visualizing alliin in the whole garlic bulb (Tab. 3). On crushing a garlic clove, alliin and allinase combine to form allicin which on storage rearranges to form diallyl sulphides and other sulphides (Lawson, 1996).

\section{Metabolism and excretion}

Allicin is completely metabolized during the first liver passage and converted to diallyldisulphide (DADS). DADS are formed immediately after starting the allicin infusion followed by the formation of allylmercaptan, a prominent metabolite of DADS (Pushpendran et al. 1980). Following garlic ingestion, DADS has been detected in the breath by gas chromatography-mass spectroscopy (Minami et al., 1989).

\section{Epidemiologic studies}

The association between consumption of garlic and risk for cancer has been assessed in several epidemiologic mainly case control studies. Human cancers have been reported, for example, in China Gangshan country, where residents consume a large amount of garlic (on average $20 \mathrm{~g}$ garlic daily). This country had the lowest gastric cancer death rates $(3.45 / 100000)$ and, in contrast, Quixia country, where little garlic is eaten, had the highest $(40 / 100000)$ (Steinmetz and Potter, 1991). In another epidemiological study from China (Nishino, 1993), a significant reduction in stomach cancers associated with increasing consumption of allium vegetables, including garlic, scallion and

Tab. 5. Effects of garlic components on carcinogenesis in experimental animals

\begin{tabular}{ccc}
\hline Organ & Carcinogen & Effect on carcinogenesis \\
\hline Forestomach & Bap & Inhibition No effect \\
\hline Colon & DMH & Inhibition \\
\hline Esophagus & NMBA & Inhibition \\
\hline Mammary gland & DMBA & Inhibition \\
\hline Lung & Bap & Inhibition \\
Liver & DMH & Inhibition \\
Skin & Bap-Croton oil & Inhibition \\
\hline
\end{tabular}

chives has been reported. Several case control studies in Asia and Europe have been conducted to assess the effect of Allium on the risk of cancer (Tab. 4).

\section{Experimental studies}

Garlic oil has been reported to inhibit proliferation and induce differentiation in human promyelocytic leukaemic cell line (HL-60) (Seki et al., 2000). Garlic oil induces NBT reducing activity and also induces the expression of CD11B, which is a marker of the differentiation of the HL-60. Garlic oil also have the ability to down regulate the cell cycle components; cyclin D and E1 and bcl-2 and c-myc which are amplified oncogene in HL-60 cells. Ajoene induces apoptosis in human leukemic cells but not in peripheral mononuclear blood cells from healthy donors. It occurs by the stimulation of peroxide generation and activation of nuclear factor $\mathrm{kBC}$.

DADS seem to be most effective at reducing the growth of human tumor cells originating from colon, lung, skin and breast. DADS are reported to produce marked inhibition of $\mathrm{N}$-methyl-N-nitrosourea induced mammary tumors in rats (Schaffer et al., 1996). DADS has been shown to inhibit the growth of $\mathrm{H}$-ras oncogenetransformed tumors in nude mice and induce differentiation in DS19 mouse erythroleukemic cells by increasing histone acetylation (Lea et al., 1999). DAS was reported to inhibit DMBA- induced HBP and fore stomach carcinogenesis. Furthermore, DAS acts as a suppressing agent during N-nitrosomethylbenzylamine- induced tumor in rats (Ludeke et al., 1992).

Khanum et al. (1998) have demonstrated the preventive effects of fresh garlic and garlic oil in wistar rats injected with a known colon carcinogen, azoxymethane. Garlic oil topically applied in the initial phase of benzo (a) pyrene induced skin carcinogen decrease the number of mice with skin tumors together with mean number of tumors (Tab. 5). Sparnins et al. (1998) showed that the allyl methyl trisulphate (AMT) of garlic oil, inhibited tumors of the lung and reduce benzo (a) pyrene (BP) induced tumor by $70 \%$. The topical application of garlic during the initiation phase of BP-induced skin tumors in Swiss albino mice, reported a reduction of tumor incidence (Sadhana et al., 1988). In addition to the alteration of carcinogen metabolism, inhibition of cell division, antioxidant activity, inhibition of lipoxygenase and cyclooxygenase have also been observed by researchers. 


\section{Pharmacological effects of garlic oil}

DADS have been used in China to treat viral infection and cryptococcal meningitis (Ross et al., 2001). Allicin, ajoene and organosulphides are effective antiprotozoans. It has been suggested that microbial cells are more affected than human cells because they do not have intracellular thiol content adequate to counterbalance the thiol oxidation by allicin and allicin-derived products (Lang and Zhang, 1981). The antibacterial activity of garlic is widely attributed to allicin. It exerts bacteriostatic effects and antifungal activity against Aspergillus niger, Candida albicans and Paracoccidiodes (Reimers et al., 1993). Allicin, ajoene are also active against Influenza $\mathrm{A}$ and $\mathrm{B}$, rhinovirus, HIV, herpes simplex virus 1 , viral pneumonia and rotovirus. Moreover, recent reports provide in vitro evidence for anti Helicobacter pyrolii effects of oil-macerated garlic constituents and allicin (Ohta, 1999).

Garlic has been used in Norway and middle Europe as a folk medicine for diabetes (Sheela and Augusti, 1992). Garlic products have got hypoglycemic activity by increasing either the pancreatic secretion of insulin from the beta-cells of the islets or by enhanced transport of blood glucose to peripheral tissues. It also acts on the carbohydrate metabolism to raise the insulin level in blood (Chang and Johnson, 1980). Hyperlipidemia or the increased serum cholesterol level is a high risk factor contributing to the development of coronary heart disease. Essential oil extracted from raw garlic when given in myocardial infarction patients, significant increase in fibrinolytic activity has been observed (Jain, 1998).

Garlic oil has been shown to lower plasma fibrinogen levels, prolonged coagulation time, inhibition of prostaglandin synthetase and lipoxygenase activity (Ali et al., 2000). Ajoene induce apoptosis in Hela cells via the stimulation of peroxidase protection and activation of nuclear factor $\kappa \mathrm{B}$. It enhances the immune system by increasing the number of Nk cells, which destroys the white cells that are cancerous or infected by viruses.

\section{Anticancer effects}

Chemopreventive agents are known to up regulate the ability of the liver to intercept and metabolize carcinogens. Induction of hepatic antioxidant enzymes by chemopreventive agents has been reported to alter tumor development at extra hepatic sites. Several mechanisms have been proposed to explain the cancer-preventive effects if Allium vegetables and related organosulphur compounds. These include inhibition of mutagenesis, modulation of enzyme activities, inhibition of DNA adduct formation, free radical scavenging and effects on cell proliferation and tumor growth.

\section{Antioxidant modulation}

Garlic oil exerts its tumor inhibitory effects by modulating lipid peroxidation and antioxidants. It has got differing effects in the target organ and host tissues that re- flect its modulatory role in cell proliferation. Garlic oil has been reported to scavenge OFR and modulate the levels of lipid peroxidation and antioxidants. Garlic oil is known to stimulate GPx activity, preventing the decrease in GSH/ GSSG ratio in epidermal cells (Perchellet et al., 1986). Further, it has also been recognized to increase intracellular GSH and induce phase II enzymes such as GST and GGT. In addition, it suppresses the formation of superoxide anion and hydrogen peroxide by increasing the activity of SOD, catalase and GPx (Borek, 2001). Thus elevation of antioxidant status by garlic oil presumably offers protection against lipid peroxidation by scavenging electrophilic moieties involved in cancer initiation to less toxic products thereby altering cancer development. In addition to antioxidant properties, garlic oil and its constituents have been reported to exert their tumor inhibitory effects by inhibiting lipoxygenase and ornithine decarboxylase (ODC) activities (Block et al., 1988).

\section{Effect on tumor proliferation}

Components of garlic also have been found to inhibit the activity of diverse character carcinogenesis during both the initiation and promotion phases of carcinogenesis. Garlic oil has been shown to cause a marked suppression of proliferation of human promyelocytic leukemia cells. The antiproliferative effect appears to be related to the induction of apoptosis. Exposure to DADS and DATS caused cells to undergo apoptosis, as determined by morphologic changes or DNA fragmentation (Sundaram and Miller, 1996). The cell cycle was also affected by DADS, which decreased the percentage of human colon tumor cells in the G1 and S phases and concomitantly increase the percentage of those in the G2/M phase. Garlic oil inhibits proliferation and induces differentiation of Hela cells. Also moreover garlic components have the ability to inhibit tumor cell growth and suppressing the formation of DNA adducts caused by chemical carcinogen (Amagase and Milner, 1993).

\section{Mutagenesis inhibition}

Methanolic garlic extracts inhibited the mutagenic activity of aflotoxin B1 in Salmonella typhimurium (Soni et al., 1997). Aqueous garlic extract also decreased the mutagenicity of 4-nitroquinoline-1-oxide in E. coli and the mutagenicity of $\gamma$-radiation, hydrogen peroxide, cumene and t-butyl hydro peroxides in Salmonella typhimurium (Knasmuller et al., 1988).

\section{Adverse effects}

Despite the large body of work on the beneficial effects of garlic, a few harmful effects of garlic and its organosulphur compounds have also been reported. There are no data from the National Toxicological Program regarding possible garlic toxicity in humans, administration of high doses of garlic extracts have been documented to cause damage to lung and liver tissues (Alnaqeeb et al., 1996). 
18

Uncooked garlic has been reported to have an irritant effect on human stomach (Desai et al., 1990).

\section{Conclusions}

As seen throughout the review, garlic presents several mechanisms of action to develop its large number of function. Over all evidence shows that garlic oil has cancerpreventive effects and also plays a critical role in the host defense system against cancers progression by immune modulation. The multiple mechanisms in chemopreventive activity of garlic oil, modulation of lipid peroxidation and antioxidants may be one of the important mechanisms by which garlic oil exerts its tumor inhibitory effects. Our literature suggests that garlic oil may be classified as a dietary anticarcinogen on the basis of epidemiological and experimental investigation. Garlic oil suppresses carcinogen-induced tumors in various organs of animals. Therefore, garlic oil has been proven to possess potent chemopreventive capability to inhibit cancers of various organs.

A major concern, which must be addressed when extrapolating animal findings to humans, is the dosage of the food or agent that is studied. Additional studies are needed on the chemopreventive functions for mechanisms, supplementation period and the practical doses of garlic in diet for human cancer prevention. Although there are evidences for several anticancer mechanisms, they are still speculative and further research is needed to support such properties and the cancer-preventive activity in experimental animals. Clinical trials are not currently available, but they could be useful for assessing the ability of garlic oil to prevent cancer or preneoplastic lesions. In addition, these trials cannot use cancer as the end point and should therefore rely on surrogate intermediate biomarkers. Such end points are not fully validated and further research is needed to develop and validate suitable Biomarkers.

\section{References}

Amagase, H. and J. A. Milner (1993). Impact of various sources of garlic and their constituents on 7, 12-dimethylbenz (a) anthracene binding to mammary cell DNA. Carcinogenesis. 14:1627-1631.

Agarwal, K. C. (1996). Therapeutic actions of garlic constituents. Med Res Rev. 16:111-125.

Alnaqeeb, M. A., M. Thomson, M. Bordia and T. Ali (1996). Histopathology effects of garlic on liver and lung of rats. Toxicol let. 85:157-164.

Augusti, K. T. (1996). Therapeutic values of onion (Allium sativum L). Indian journal of experimental biology. 34:634640.

Ali, M., M. Thomson and M. Afzal (2000). Garlic and onions: their effect on eicosanoid metabolism and its clinical relevance. Fatty acids. 62:55-73.

Block, E., R. Iyer, S. Grisoni, C. Saha, S. Belman and F. P.
Lossing (1988). Lipoxygenase inhibitors from the essential oils of garlic markovnikov addition of the allyl dithio radical to olefins. Journal of American Chemical Society. 110:78137827.

Bianchini, F. and H. Vainio (2001). Allium vegetables and organosulfur compounds: do they help prevent cancer? Environmental Health Perspectives. 109:893-902.

Borek, C. (2001). Antioxidant health effects of aged garlic extract. Journal of Nutrition. 131:1010-1015.

Chang, M. L. and M. A. Johnson (1980). Effect of garlic on carbohydrate metabolism and lipid ynthesis in rats. Journal of Nutrition. 5:931-936.

Desai, H. G., R. H. Kalro and A. P. Choksi (1990). Effect of ginger and garlic on DNA content of gastric aspirate. Indian Journal of Medical Research. 92:139-141.

Heber, D. (1997). The stinking rose: organosulphur compounds and cancer. American Journal of Clinical Nutrition. 66: 425-426.

Harris, J. C., S. L. Cottrell, S. Plummer and D. Lloyd (2001). Antimicrobial properties of Allium sativum (garlic). Applied Microbiology and Biotechnology. 57:282-286.

Jain, R. C. (1998). Anti tubercular activity of garlic oil. Indian Journal of Pathology and Microbiology. 1:123-131.

Knasmuller, S., R. Demartin, G. Somjan and A. Szakmary (1988). Studies on the antimutagenic activities of extract. Environmental Molecular Mutagenesis. 13:357-365.

Khanum, E., K. R. Anilakumar, K. R. Sudarshanakrishna and K. R. Viswanath (1998). Effects of feeding fresh garlic and garlic oil on detoxifying enzymes and micronuclei formation in rats treated with azoxymethane. International Journal of Vitamins and Nutritional Research. 68:208-213.

Lang, Y. J. and Y. Zhang (1981). Studies on the effective components of garlic (Allium sativum). China Herbs and Medicine. 4:4-6.

Ludeke, B. I., F. Domine, H. Ohgaki and P. Kleihues (1992). Modulation of $\mathrm{n}$-nitrosomethyl benzylamine bioactivation by diallyl sulphide in vivo. Carcinogenesis. 13:2467-2470.

Lawson, L. D. (1996(. The composition and chemistry of garlic cloves and processed garlic. p.37-107 In: H.P. Koch and L.D Lawson (eds.). Garlic: The science and therapeutic application of Allium sativum L. and related species. 2nd ed., Williams and Wilkins.Baltimore.

Lea, M. A., V. M. Redolph and M. Patel (1999). Increased acetylation of histones induced by diallyl sulphide and structurally related molecules. International Journal of Oncology. 15:347-352.

Minami, T., T. Boku, K. Inada, M. Morita and Y. Okazaki (1989). Odour componenets of human breath after the ingestion of grated raw garlic. Journal of Food Science. 54: 763-765.

Nishino, H. (1993), p. 290-294. In: Cancer preventive agents in processed garlic. Food and cancer prevention: chemical and biological aspects, Waldron, K.W.Johnson, I.T.Fenwick, 
G.R. (eds.). Cambridge: Royal Society of Chemistry.

Ohta, R. (1999). In vitro inhibition of the growth of helicobacter pyroli by oil macerated garlic constituents. Antimicrobial agents Chemotherapy. 43: 1811-1812.

Pushpendran, C. K., T. P. A. Devasagayam, G. J. Chintalwar, A. Banerji and J. Eapen (1980). The metabolic fate of [35s] -diallyl disulphide in mice. Experientia. 36:1000-1001.

Perchellet, E. M., N. L. Abney, J. A. Zirnstein and S. Belman (1986). Effects of garlic and onion oils on glutathione peroxidase activity, the ratio of reduced/ oxidized glutathoione and ornithine decarboxylase induction in isolated mouse epidermal cells treated with tumor promoters. Cancer Biochemistry and Biophysics. 8:299-312.

Reimers, F., S. E. Smolka, S. Werres, K. Plank-Schmacher and G. Wagner (1993). Effect of ajoene, a compound derived from Allium sativum on phytopathogenic and epiphytic microorganisms. Zpflanzenkrankh Pflanzenschutz. 100:622-633.

Ross, Z. M., E. A. Ogara, D. J. Hill, H. V. Sleightholme and D. J. Maslin (2001). Antimicrobial properties of garlic oil against human enteric bacteria: evaluation of methodologies and comparisons with garlic oil sulfides and garlic powder. Applied Environmental Microbiology. 67:475-480.

Sadhana, A. S., A. R. Rao, K. Kucheria and V. Bijani (1988). Inhibitory action of garlic oil on the initiation of benzo(a) pyrene- induced skin carcinogenesis in mice. Cancer Letters. 40:193-197.
19

Sparnins, V. L., A. W. Mott, G. Barany and L. W. Wattenberg (1988). Effects of allyl methyl trisulfide on glutathione-stransferase activity in mouse. Carcinogenesis. 9:131-134.

Steinmetz, K. A. and J. D. Potter (1991). Vegetables, fruit and cancer mechanisms. Cancer Causes Control. 2:427-442.

Sheela, C. G., K. T. Augusti (1992). Antidiabetic effects of s-allyl cysteine sulphoxide isolated from garlic Allium sativum Linn. Indian Journal of Experimental Biology. 6:523-526.

Schaffer, E. M., J. Liu, J. Green, C. D. A. Dangler and J. A. Milner (1996). Garlic and associated allyl sulphur components inhibit n-methyl-n-nitrosourea- induced rat mammary. carcinogenesis. Cancer Letters. 102(1-2):199-204.

Sundaram, S. G. and J. A. Miller (1996). Diallyl disulphide induces apoptosis of human colon tumor cells. Carcinogenesis. 17: 669-673.

Soni, K. S., M. Lahiri, P. Chackradeo, S. V. Bhide and R. Kuttan (1997). Protective effect of good additives on aflatoxin induced mutagenecity and hepatocarcinogenicity. Cancer Letters. 115:129-133.

Schorah, C. J. (1999). Micronutrients, vitamins and cancer risk. Vitamins and Hormones. 57:1-23.

Seki, T., K. Tsuji, Y. Hayato, T. Moritomo and T. Ariga (2000). Garlic and onion oils inhibit proliferation and induce differentiation of hl-60 cells. Cancer Letters. 160:29-35. 